\title{
Robustness of Prefabricated Prefinished Volumetric Construction (PPVC) High-rise Building
}

\author{
Y. S. Chua ${ }^{a *}$, J. Y. R. Liew ${ }^{a, b}$ and S. D. Pang ${ }^{a}$ \\ ${ }^{a}$ Department of Civil and Environmental Engineering, National University of Singapore, Singapore \\ ${ }^{b}$ College of Civil Engineering, Nanjing Tech University, Nanjing, China \\ *corresponding author, e-mail address: ceecysue@nus.edu.sg
}

\begin{abstract}
Due to the safety awareness arisen from natural and human-caused disasters, robustness design of building is increasingly important to ensure the stability of the building and to prevent progressive collapse. For this reason, the robustness design of innovative construction technologies such as modular construction may be essential due to its relative novel structural form and numerous joints among modules. Particularly in Singapore, Prefabricated Prefinished Volumetric Construction (PPVC) has been highly promoted in residential and commercial buildings, hostels and hospitals to boost the construction productivity and quality as well as to reduce the reliance on foreign workforce. PPVC offers high quality and efficiency because most of the finishes and mechanical and electrical services are manufactured and installed together with the modules in factory, before sending for on-site assembly. To maximize the productivity of PPVC, modular design standardization and repetition can be improved by going for high-rise. Nonetheless, there are limited studies on the robustness of PPVC high-rise building and its behavior under progressive collapse remains uncertain. Therefore, this paper investigates the robustness of steel PPVC high-rise building under column removal scenarios by conducting non-linear numerical analysis. The effects of joint design and diaphragm action between modules are studied to ensure continuity of horizontal and vertical tying. This paper provides insight on the behaviour and alternative path for load transfer under column removal scenario for future design guideline of robustness PPVC building.
\end{abstract}

Keywords: Modular; High-rise; Robustness; Column removal; Pushdown.

\section{Introduction}

Robustness is described as the ability of the structure to withstand the action of extreme events without being damaged to an extent disproportionate to the original cause under the Eurocode [1]. Progressive collapse is defined by DoD [2] in the Unified Facilities Criteria (UFC) as the spread of an initial local failure from element to element, eventually resulting in the collapse of an entire structure or a disproportionately large part of it. Buildings with inadequate robustness are vulnerable to unanticipated extreme loads or hazards. Research on robustness and progressive collapse analyses has been intensified over the last two decades due to the several high profile collapses of multi-storey buildings caused by abnormal loads [3-6]. Some of the major progressive collapse incidents occurred in the past were: (i) partial progressive collapsed of 22-storey Ronan Point apartment in UK due to domestic gas explosion, (ii) 9-storey reinforced concrete Murrah Federal office building at Oklahoma City collapsed due to a truck-bomb attack, and (iii) World Trade Centre twin towers and World Trade Centre 7 collapsed due to terrorist attack.

However, little research has been done on the robustness of newer building technologies such as Prefabricated Prefinished Volumetric Construction (PPVC). PPVC is one of the gamechanging technologies that support the concept of Design for Manufacturing and Assembly (DfMA). Modular is a general construction term associated to it, describing the use of technology 
that facilitates off-site manufacturing. Complete modules made of multiple units complete with internal finishes, fixtures and fittings are manufactured in factories, and are then transported to site for installation in a Lego-like manner. Aside from enhancing construction productivity, PPVC also delivers significant advantages in on-site safety, quality control and sustainability [7].

Unlike conventional steel frames, there is discontinuity in the structural elements at the connections between modules due to the way they are installed. The nature of PPVC creates multiple floor diaphragms instead of the otherwise single rigid diaphragm present in conventional buildings. The discontinuity in the structural elements and floor slab diaphragms has an adverse effect on the development of catenary forces in beams, which causes improving a structure's progressive collapse resistance. Furthermore, there is an abundance of complex connections in a single PPVC building. Modular units are generally connected via the four corners of the unit using plates and bolts. This raises the question of the joints' ductility during a progressive collapse.

A research done by [7] studied the robustness of modular construction by adopting a scenariobased approach in which modules are selectively removed. His work indicates that typical modules possess sufficient shear capacity to cantilever damaged sections of the building. It was concluded that the alternate load path method was the most appropriate means by which modular construction can comply with the regulations for robustness [7]. However, tests carried out by Lawson et al. [7] did not consider the geometric nonlinearity and overall response of a building under progressive collapse. This calls for further research to be done on the robustness of modular construction. Moreover, the limited research in this area needs to be boosted to meet the growing consensus in the structural engineering community that there is a need to quantify robustness for all buildings.

Therefore, this study aims to study the robustness and progressive collapse analyses in PPVC buildings. To achieve this goal, numerical models simulating a 40-storey steel frame PPVC building are developed using ETABS software. The simplified framework is put under progressive collapse assessment by considering structural column loss as a design scenario (Fig.
1) using nonlinear static pushdown analyses. From there, the progressive curves are studied to analyze the robustness and mechanical behavior of the building.

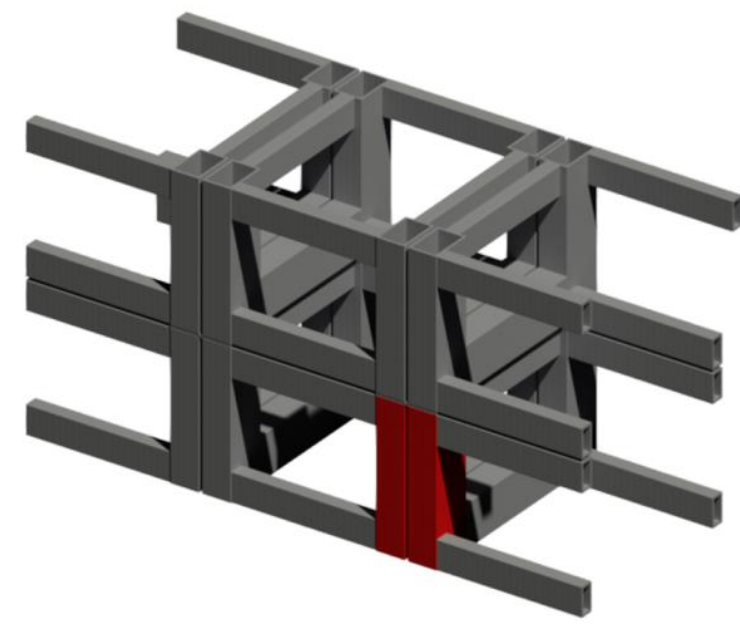

Fig. 1. Illustration of columns, in red, to be removed in a simple PPVC framework.

\section{Pushdown analysis}

Alternate Path Method (APM) is commonly used in design guidelines for minimizing the potential for vertical progressive collapse and it is performed by removing a critical structural element one at a time to check the bridging capability of structure over the missing element [8]. The methodology is generally applied in the context of a 'missing column' scenario to assess the potential for progressive collapse and used to check if a building can successfully absorb loss of a critical member [9, 10]. In this study, pushdown analysis is chosen to study the progressive collapse of PPVC building because of its ability to account for nonlinear effects and determine elastic and failure limits of the structure [9].

There are two types of loading way in pushdown analysis: uniform pushdown and bay pushdown [9]. In the uniform pushdown analysis, gravity loads on the damaged structure are increased proportionally until the ultimate limit occurs as depicted in Fig. 2(a). The failure may occur outside the damaged bays, and thus it might not be possible to estimate the residual capacity of the damaged bay. Whereas for bay pushdown analysis as shown in Fig. 2(b), the gravity load is increased proportionally only in the bays that suffer damage until the ultimate limit is reached in the damaged bays. 
Column removed

(a)

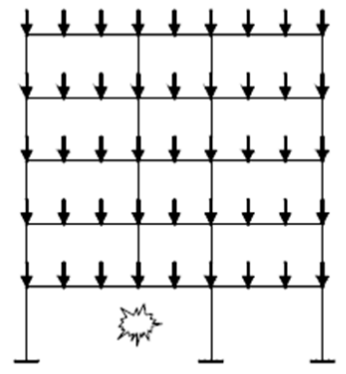

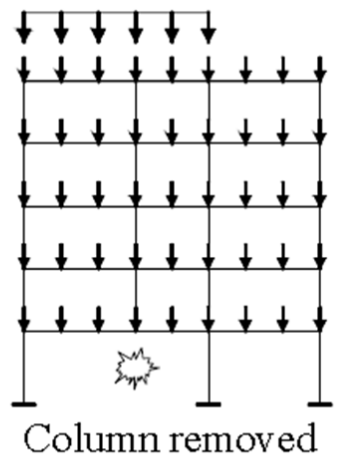

(b)
Fig. 2. Schematic of pushdown analysis: (a) uniform and (b) bay [9].

In this study, bay pushdown analysis is used to analyse the effects of duration and instant of element removing as well as the locations of the removed elements. Force-controlled nonlinear static analysis procedure is adopted. This analysis method follows a loading procedure of which the vertical loads which are shown in Eqs. 1 and 2 are increased incrementally (in at least 10 load steps) until maximum loads are attained or until the structure collapses. This maximum amplified loads in the nonlinear static analysis procedure deemed by General Services Administration Progressive Collapse Guidelines [8]. As shown in Eq. 2, amplification factor of 2 is applied on the floor areas above the removed column whereas a value of 1 for other floor areas.

Floor areas away from removed column:

Load $=(1.2 D L+0.5 L L)$

Floor areas above removed column:

Load $=2(1.2 D L+0.5 L L)$

where $D L$ refers to the vertical dead loads and $L L$ is the vertical live loads.

Plastic hinges are assigned to the ends of each member. ETABS flexural hinge properties are assigned to both ends of each beam element. Default moment-hinge properties based on FEMA [11] guidelines were adopted for the hinge model, as shown in Fig. 3. The deformation and acceptance criteria of plastic hinges shall be the deformation corresponding to the points as displayed in Fig. 3.

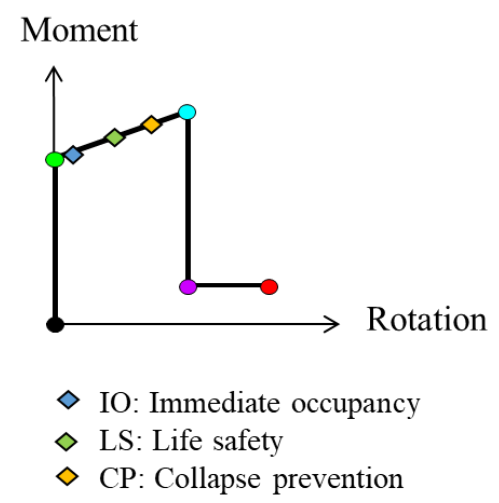

Fig. 3. Plastic hinge model.

\section{PPVC model description}

A 40-storey residential building is selected in this study as shown in Fig. 4. The steel PPVC modules consist of ceiling level and floor level (as displayed in Fig. 5) and are arranged around coupled core walls. Table 1 shows the structural member size used in this building. Coupled core wall is selected due to its higher stiffness and strength resulting from coupling effects. The horizontal forces are resisted through a combination of flexural action of the walls and frame action between the coupling beams and the walls, resulting in better performance than uncoupled walls that contribute their stiffness and strength separately. In this design, it is assumed that the core walls resist most of the lateral load to ensure the stability of the high-rise building, whereas PPVC modules take most of the gravity load. Moreover, as the modules are connected at the joints only, hence each module represents single floor diaphragm as displayed in Fig. 5(b).

As mentioned above, the PPVC modules in this study are made of corner-supported modules and they are connected to each other via corner joints. To ensure the robustness and stability of a module, the beams must be rigidly connected to the columns within a module. It can be done conveniently and in good quality by welding as the manufacturing of the modules are conducted in factory. To tie the adjacent modules (e.g. horizontal tying) as well as upper and lower modules (e.g. vertical tying), a joining technique using vertical reinforcement, shear key, and gusset plate as shown in Fig. 6, is commonly found in steel PPVC building in Singapore. An advantage of this connection is that it is entirely externally accessed, which means that there is no need to do any works (i.e. bolting or welding) on the inside of the prefinished modules. As can be 
seen in Fig. 6, rebars which are secured via nuts at each level run vertically through the modules. This ensures vertical continuity and allows the transfer of moment from the modules down to the foundation. Shear forces are transferred between vertically stacked modules via the bearing of the bottom shear key against the top base plate. For horizontal tying, on the other hand, horizontal continuity is provided for by the gusset plate that connects adjacent modules. Shear and axial forces are transferred between the modules via the bearing of shear keys against the connecting gusset plate. Rotational stiffness of rebar was calculated analytically. Referring to Eurocode 3 [12], it is stated that a rotational connection between two members can be classified as "pin", "semi-rigid", or "fixed" based on how the joint rigidity compares with the flexural rigidity of the structural members involved. Comparing both the rotational stiffness obtained with the guidelines stipulated in Eurocode, it is found that the joint can be idealized to be "pin" in both major and minor axis rotation for vertical tying. Conversely, the joint is assumed as rigid for horizontal tying. Based on these assumptions, simplified connection modeling used in ETABS is displayed in Fig. 7.

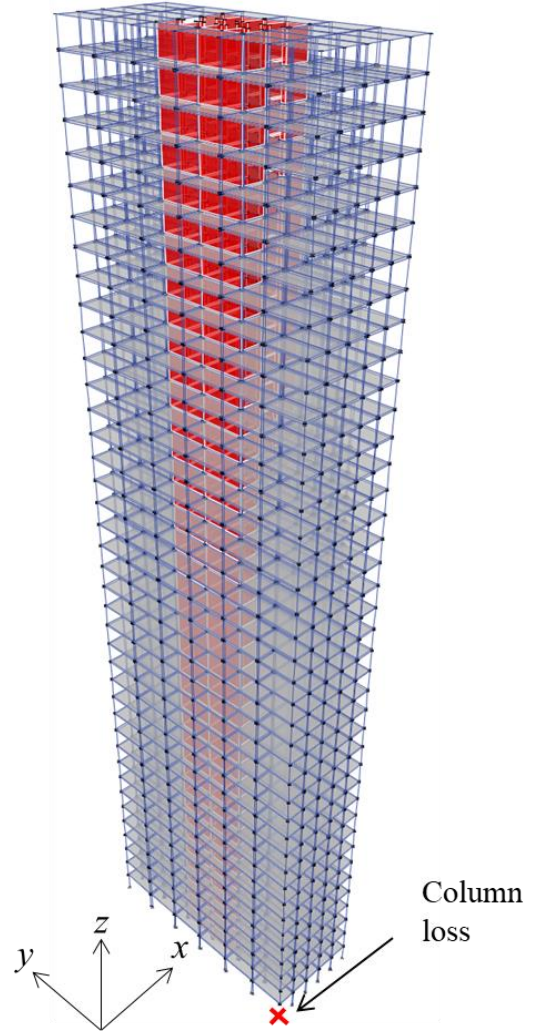

Fig. 4. 40 storey residential steel PPVC building.

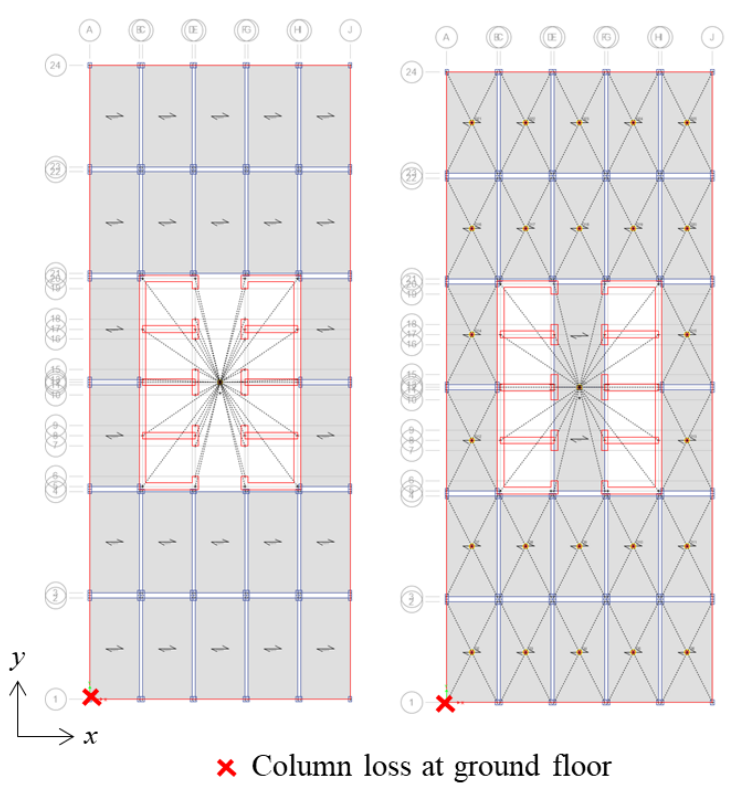

(a)

(b)

Fig. 5. Plan view (a) ceiling level, and (b) floor level.

Table 1. Structural member size.

\begin{tabular}{|c|c|}
\hline Member & Size \\
\hline Ceiling beam & SHS $150 \times 150 \times 5$ \\
\hline Floor beam & RHS $200 \times 150 \times 10$ \\
\hline $\begin{array}{c}\text { Column } \\
\text { (Level 1- 10) }\end{array}$ & RHS $300 \times 20 \times 16$ \\
\hline $\begin{array}{c}\text { Column } \\
\text { (Level 11-40) }\end{array}$ & RHS $300 \times 20 \times 10$ \\
\hline
\end{tabular}

\section{Results and discussion}

Bay pushdown analysis of abovementioned 40 -storey residential building is carried out. The corner column at the ground floor of the building is removed as shown in Figs. 4 and 5, to investigate the alternate path of the building. This is because corner column loss scenario tends to be more susceptible to progressive collapse compared to intermediate column loss scenarios [13]. Fig. 8 shows the deformation and high formation in PPVC high-rise building subjected to corner column removal. In the pushdown analysis, the plastic hinges are firstly formed in floor beams of the damaged areas, eventually followed by ceiling beams. The floor and ceiling beams act as cantilever structures due to the removal of column as shown in Fig. 8. In particular, the floor beam develops hinges first, followed by ceiling beams because the initial loading on the floor beam would have already induced a much higher bending moment, 

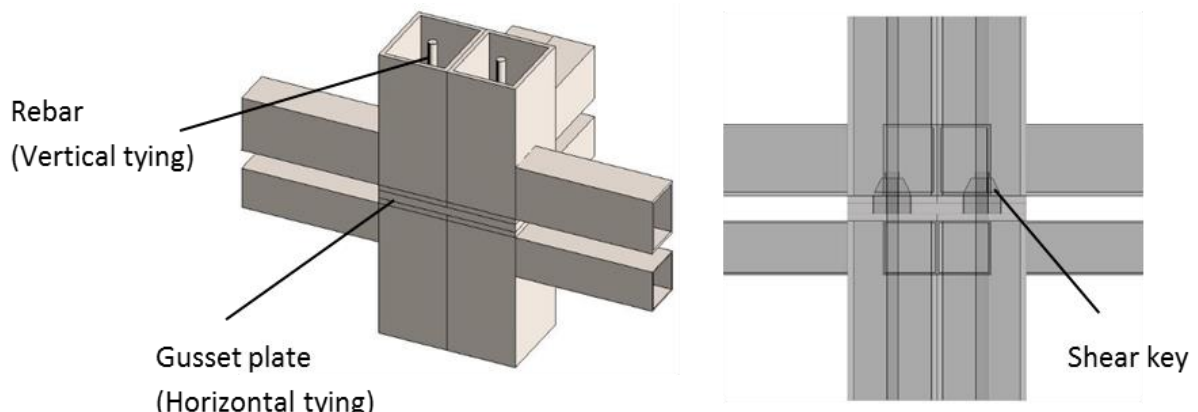

Fig. 6. Joining technique using vertical reinforcement, shear key, and gusset plate.

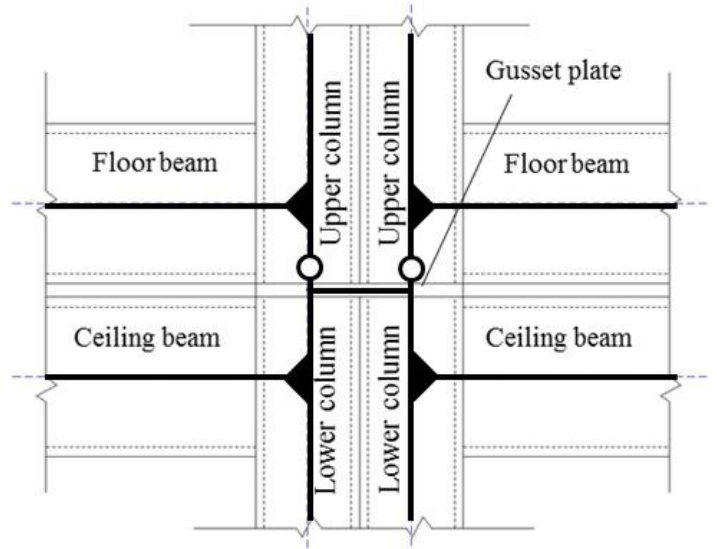

Fig. 7. Illustration of simplified model of joint in ETABS.

so it reaches its plastic moment capacity first. It can also be observed that the hinges develop predominantly and reach their plastic capacities faster in the beams than columns, since the section depth of the column is large enough to provide a much larger moment capacity than the beams. This demonstrates a "weak beam/strong column" mechanism that gives a more desirable

structural performance than a "strong beam/weak column" mechanism, which may lead to large deformations and second order effects [14]. All the plastic hinges not reach immediate occupancy (IO) level at 100\% GSA loading as referring to Fig. 3. This shows that PPVC building subjected to column loss is robust enough to prevent progressive collapse based on GSA and FEMA guidelines [8, 11]. This may be due to the double beams system (e.g. floor and ceiling beams) in PPVC building, resulting in redundancy of the structure. This is different from conventional building whereby each level only consists of one beam.

Catenary action refers to the ability of beams to resist vertical loads through formation of a catenary-like, or cable-like mechanism [15].
This occurs under large deformation whereby the applied loads are predominantly resisted by the vertical components of axial forces that develop in the beams., instead of flexural behaviour. Catenary action can be developed when the column is strong such that it is unsusceptible to buckling. As observed, floor beams located in the affected bays are subjected to axial force to resist the applied loads and transfer them to the adjacent columns. Furthermore, the robustness of the modules, specifically on catenary action is enhanced due to the rigid diaphragm provided by the floor. It should be noted that the design of joining technique, particularly for gusset plate, needs to provide sufficient resistance such that the modules are tied together to develop alternate path under column loss because the modules are only connected at the joints by gusset plates and they acts as separate diaphragm.

\section{Conclusion}

The robustness of PPVC high-rise building are studied using pushdown analysis under corner column removal scenario. It is found that plastic hinges are formed in floor beams, followed by ceiling beams located at the affected bays. Moreover, catenary action is developed when the floor beams are subjected to axial force such that the applied load can be transferred to adjacent columns. It can be concluded PPVC high-rise building is robust enough to prevent progressive collapse due to the high redundancy of structural elements.

\section{Acknowledgement}

The authors would like to acknowledge the financial support by the National Research Foundation (NRF) and SembCorp-NUS Corp Lab under project grant R-261-513-009-281. 


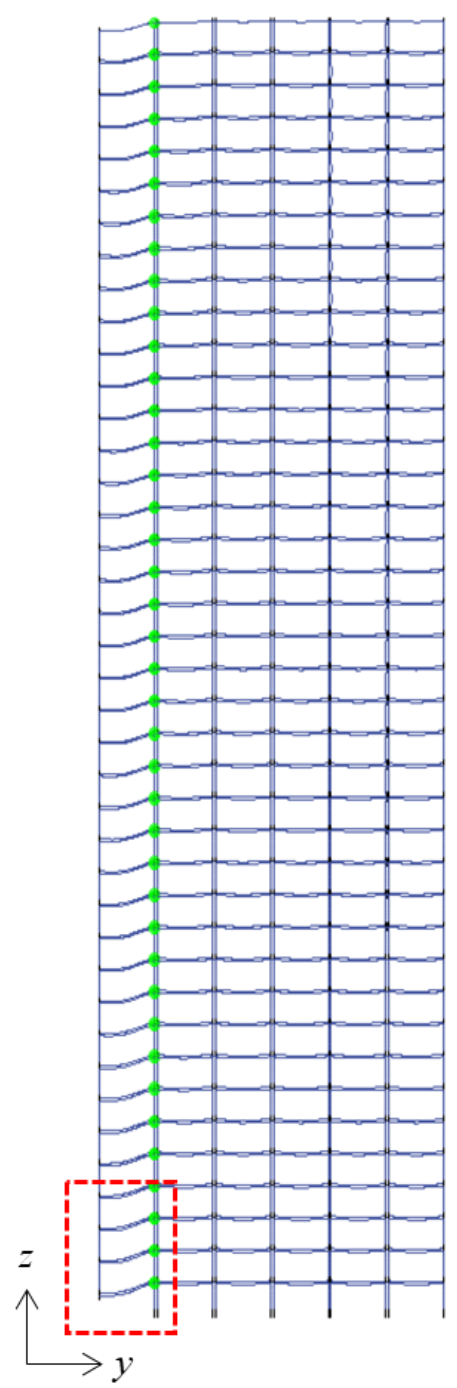

(a)

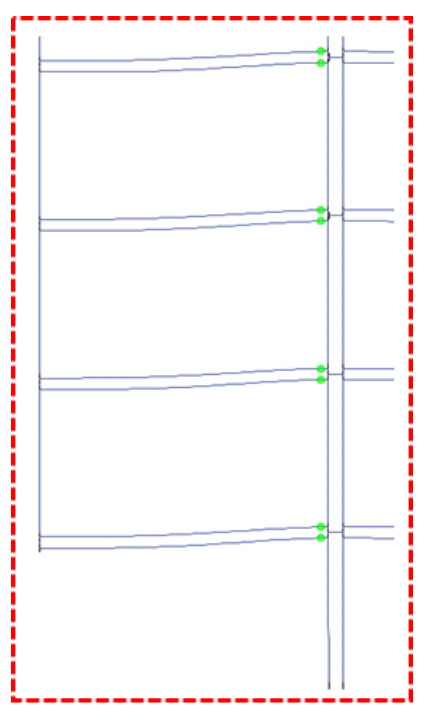

(b)

Fig. 8. Plastic hinge distribution at $100 \%$ GSA load (a) Whole building, and (b) closedup at most severe part.

\section{References}

[1] British Standards Institution (BSI). BS EN 19911-1-7:2006+A1:2014 Eurocode 1 - Actions on structures - Part 1-7: General actions Accidental actions; 2014.

[2] Department of Defence (DoD). Unified Facilities Criteria (UFC): Design of buildings to resist progressive collapse. Unified Facilities Criteria (UFC) 4-023-03; 2009.

[3] Izzuddin BA, Vlassis AG, Elghazouli AY Nethercort DA. Assessment of progressive collapse in multi-storey buildings. Proceedings of the ICE - Structures and Buildings 2007;160(4):197-205.

[4] Izzuddin BA, Vlassis, AG, Elghazouli AY, Nethercort DA. Progressive collapse of multistorey buildings due to sudden column loss. Part I: Simplified assessment framework. Engineering Structures 2008;30(5):1308-1318.

[5] Jeyarajan S, Liew JR, Koh CG. Progressive collapse mitigation approaches for steel-concrete composite buildings. International Journal of Steel Structures 2015;15(1):175-91.

[6] Jeyarajan S, Liew JR, Koh CG. Enhancing the robustness of steel-concrete composite buildings under column loss scenarios. International Journal of Protective Structures 2015;6(3):52950.

[7] Lawson PM, Byfield MP, Popo-Ola SO, Grubb PJ. Robustness of light steel frames and modular construction. Proceedings of the ICE - Structures and Buildings 2008;161(1):3-16.

[8] General Services Administration (GSA). GSA: Alternate path analysis and design guidelines for progressive collapse resistance. U.S. General Services Administration (GSA); 2013.

[9] Lu DG, Cui SS, Song PY, Chen ZH. Robustness assessment for progressive collapse of framed structures using pushdown analysis methods. International Journal of Reliability and Safety 2011;6(1-3):15-37.

[10] Jeyarajan S, Liew JR, Koh CG. Plastic hinge analysis of composite frames under column loss scenario. International Journal of Steel Structures 2016;16(3):975-85.

[11]Federal Emergency Management Agency, FEMA-356. Prestandard and commentary for seismic rehabilitation of buildings. Washington (DC); 2000.

[12] European Committee for Standardization (CEN). Eurocode 3: Design of steel structures. Eurocode; 2005.

[13] Mohamed OA. Assessment of progressive collapse potential in corner floor panels of reinforced concrete buildings. Engineering Structures 2009;31(3):749-757. 
Chua, Y.S., Liew, J.Y.R. and Pang, S.D.

[14] Elghazouli AY. Seismic design of buildings to Eurocode 8. CRC Press; 2016.
[15] Khandelwal K, El-Tawil S. Pushdown resistance as a measure of robustness in progressive collapse analysis. Engineering Structures 2011;33(9):2653-61. 